\title{
Strengthening implant provision and acceptance in South Africa with the 'Any woman, any place, any time' approach: An essential step towards reducing unintended pregnancies
}

\author{
H Rees, ${ }^{1}$ MB BChir, MA (Cantab), MRCGP, DCH, DRCOG; Y Pillay, ${ }^{2}$ PhD; $\mathbf{S}$ Mullick, ${ }^{1}$ MB ChB, MSc, MPH, PhD; \\ M F Chersich, ${ }^{1} \mathrm{MB} \mathrm{BCh}, \mathrm{PhD}$ \\ ${ }^{1}$ Wits Reproductive Health and HIV Institute, Faculty of Health Sciences, University of the Witwatersrand, Johannesburg, South Africa \\ ${ }^{2}$ National Department of Health, Pretoria, South Africa
}

Corresponding author: H Rees (hrees@wrhi.ac.za)

\begin{abstract}
Progress in reducing unintended pregnancies in South Africa is slow. The implant, introduced in 2014, expanded the range of available longacting reversible contraceptives (LARCs) and held much promise. Uptake, however, has declined precipitously, in spite of its 'unmatched effectiveness' and high levels of satisfaction for most users. We propose policy and provider interventions to raise implant use, underscored by a 'LARC-first' approach. Contraceptive counselling should focus on the particular benefits of LARCs and methods be presented in order of effectiveness. Moreover, implants hold particular advantages for certain groups, especially adolescents and young women, in whom it is considered first-line contraception. Provision of immediate postpartum and post-abortion implants is safe and highly acceptable, yet remains under-utilised. Implant services at HIV and tuberculosis clinics are a key priority, as is inclusion of LARC provision within school health services. Implants could also be delivered by existing mobile outreach services, for example in sex worker programmes. Services could be built around nurses dedicated solely to providing implants, with other health workers receiving brief refresher training. Women who experience side-effects, especially abnormal bleeding, require timely interventions, following a standardised protocol, including use of medications. Encouraging return for side-effects, follow-up phone calls and home visits would raise continuation rates. Removal services require doctor support or designated nurses at specific centres. Limited access to removal services, health workers' resistance or botched procedures will further undermine implant provision. Rapid implant demonstration projects in postpartum wards, schools, outreach services and by dedicated providers may rapidly advance the field. Together, the actions outlined here will ensure that the implant fulfils its potential and reinvigorates family planning services.
\end{abstract}

S Afr Med J 2017;107(11):939-944. DOI:10.7196/SAMJ.2017.v107i11.12903

Despite the launch of a new national contraceptive policy in 2012 and the introduction of the implant contraceptive in 2014, ${ }^{[1]}$ South Africa (SA) is making slow progress in reducing levels of unintended pregnancies, including among teenagers. ${ }^{[2]}$ Implants and the intrauterine device (IUD), both referred to as long-acting reversible contraceptives (LARCs), have much greater effectiveness than short-acting alternatives. ${ }^{[3,4]}$ Oral contraceptives, for example, have contraceptive failure rates as high as $20 / 100$ woman-years ${ }^{[5]}$ compared with a failure rate of $0.05 \%$ for the implant and $0.8 \%$ for the copper IUD. ${ }^{[4]}$ Given the 'unmatched effectiveness ${ }^{\text {[ }}{ }^{6]}$ of implants and continuation rates of $\sim 80 \%$ at 1 year in multiple assessments globally, ${ }^{[4,7,8]}$ some proponents consider implants - alongside IUDs - to be 'first-line' contraceptives, and other methods as 'second-tier. ${ }^{\left[{ }^{[]}\right.}$ Indeed, professional bodies in the USA recommend that providers must emphasise that LARCs are 'the best reversible methods for preventing unintended pregnancy, rapid repeat pregnancy, and abortion in young women. ${ }^{[10,11]}$ In SA, Implanon is currently used to provide pregnancy protection for 3 years, but increasingly evidence suggests that protection may extend to 5 years, even in women with a high body mass index. ${ }^{[12,13]}$ Prolonged effectiveness would further improve Implanon's convenience for women, and reduce removal procedures and costs of implant replacements.

Despite the effectiveness and programmatic advantages of the implant, its promise has not been realised in SA. The number of implants inserted in the public sector has fallen from $\sim 175000$ in
2014/2015 to only 50000 in 2016/2017, ${ }^{[14]}$ with declines noted in all provinces of the country (Fig. 1). Levels of uptake have been especially low in Mpumalanga, the Northern Cape and North West Province since the introduction of the implant. Similar concerns prevail around the copper IUD, which accounts for only $2 \%$ of all contraceptive use,

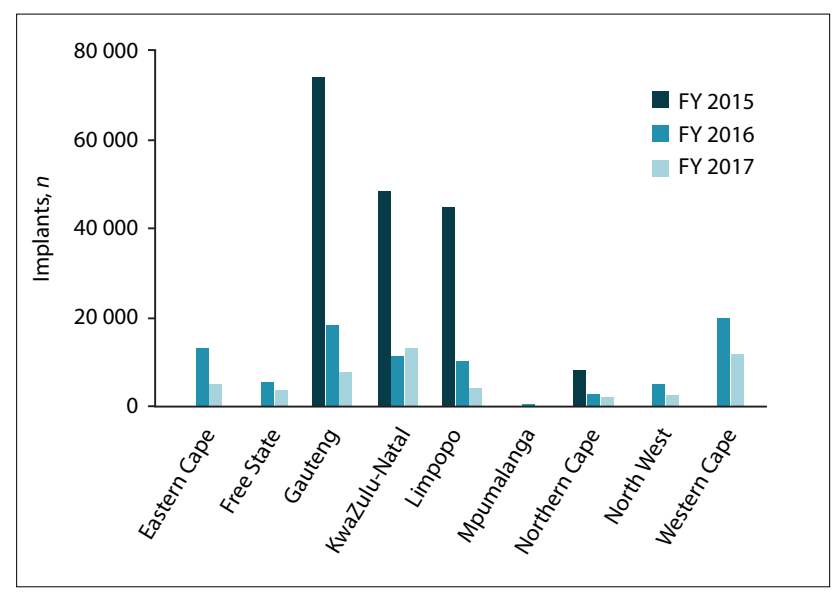

Fig. 1. Total numbers of implant insertions for each province in South Africa from April 2014 to March 2017 $7^{[14]}$ (no data are available for the Eastern Cape, the Free State, North West, or the Western Cape for financial year 2015). ( FY = financial year. $)$ 
Table 1. 'Any woman, any place, any time' approach: Addressing the patient, system and provider barriers to implant initiation and continuation

\begin{tabular}{|c|c|c|}
\hline Target population groups & Settings for implant provision & Health workers \\
\hline $\begin{array}{l}\text { Women attending family planning clinic, including first- } \\
\text { time users, women unsure about method, and women } \\
\text { seeking renewal of short-acting method }\end{array}$ & $\begin{array}{l}\text { Family planning clinics and primary healthcare } \\
\text { clinics }\end{array}$ & $\begin{array}{l}\text { Primary care nurses, dedicated } \\
\text { LARC providers, and } \\
\text { doctors (removals) }\end{array}$ \\
\hline Adolescents and young women & $\begin{array}{l}\text { Schools, youth-friendly services, campus clinics } \\
\text { and technical colleges }\end{array}$ & $\begin{array}{l}\text { School health nurses, } \\
\text { dedicated LARC providers }\end{array}$ \\
\hline Postpartum women & $\begin{array}{l}\text { Labour wards (demand generated in ante- } \\
\text { natal clinics) }\end{array}$ & $\begin{array}{l}\text { Midwives (labour wards and } \\
\text { antenatal clinics) }\end{array}$ \\
\hline Post-abortion women & Termination-of-pregnancy wards & Nurses \\
\hline Special target populations, such as HIV-infected women, & Mobile outreaches & Dedicated LARC providers, \\
\hline TB patients, sex workers & HIV and TB clinics & $\begin{array}{l}\text { CHWs, and HIV lay } \\
\text { counsellors }\end{array}$ \\
\hline Communities & Community settings, households & $\begin{array}{l}\text { CHWs, and HIV lay } \\
\text { counsellors }\end{array}$ \\
\hline
\end{tabular}

mainly because of limited nurse training in insertion and suboptimal access in family planning clinics. ${ }^{[15]}$ In addition, the longstanding question of whether depot medroxyprogesterone acetate (DMPA) increases women's risk for HIV acquisition will soon be answered by the Evidence for Contraceptive Options and HIV Outcomes (ECHO) study. ${ }^{[16]}$ If a significant association is demonstrated, there may be a compelling reason to restrict the provision of injectables for women at high risk of HIV infection.

Against this background, SA needs to redouble its efforts to improve contraceptive access for all women, especially to LARCs. This commentary therefore proposes a new approach for SA, described by Hathaway et al. ${ }^{[17]}$ centring on the concept of 'Any woman, any place, any time', which holds that women should have access to LARCs in a range of complementary settings. We outline the policy, systems and provider interventions required to support this approach (Table 1). ${ }^{[18]}$

\section{Building the workforce for implant provision}

A range of health worker cadres are required, including staff dedicated solely to LARC provision. In Zambia, retired midwives were placed at high-volume, public-sector facilities solely to provide LARCs. Only 18 of these facilities were able to insert $>22000$ implants in 14 months, which is nearly half of the number inserted in all of SA in 2016/2017. ${ }^{[19]}$ As dedicated providers have the necessary time and skills - and a mandate - they were able to generate demand, provide quality services and guide the work of other family planning staff. ${ }^{[19]}$ Dedicated providers cannot function in isolation and require tightly ring-fenced time, sufficient clients, supplies and supervision to allow them to maintain competency, confidence and productivity. ${ }^{[20]}$ In many parts of sub-Saharan Africa, dedicated providers also deliver implant services through mobile outreaches, which can rapidly increase implant uptake. ${ }^{[8,21]}$ Existing outreach services in $\mathrm{SA}$, for example to schools and among groups such as female sex workers ${ }^{[22]}$ provide a solid platform for such services. Projects piloting provision of implants in outreach services and through dedicated providers are needed.

While implant provision is built around nurses, doctors need to play a larger role, especially regarding removal procedures. Furthermore, in several settings in Africa and Asia, LARC services rely heavily on community health workers (CHWs). ${ }^{[23-25]}$ They lead community-based distribution of the implant, visit users' homes and provide support for women experiencing side-effects. A study in rural Northern Nigeria, where CHWs were tasked with inserting implants, showed the importance of frequent supervisory visits for CHWs. ${ }^{[24]}$ In the absence of such support, CHWs reverted to dispensing shorter-acting methods. ${ }^{[26]}$ CHWs in SA, especially at 'primary healthcare re-engineering' sites, ${ }^{[27]}$ and HIV lay counsellors - already adept at 'task shifting' - could play an important role in implant services through demand creation, conducting pre-insertion counselling around LARCs and providing follow-up support.

Brief, carefully designed training can raise uptake and continuation of the implant. A cluster-randomised trial involving 40 clinics in the USA demonstrated the effectiveness of a half-day training intervention of healthcare workers. Following the training, twice as many women chose a LARC method and subsequent rates of unintended pregnancy were cut by $50 \%$ compared with controls. ${ }^{[28]}$ Training in this and other instances have included orientation to tools such as procedural checklists, contraceptive effectiveness charts, clinical case discussions, practical training with anatomical models and audiovisual materials. ${ }^{[29]}$ To be effective, however, training does need to be carefully planned and accompanied by other interventions to strengthen service delivery. In a study in Bangladesh, for example, training was largely ineffective, as health system weaknesses constrained the potential for service improvements. ${ }^{[30]}$ SA data also indicate that training that is too short and does not include management of side-effects and removals, may be inadequate to support implant provision. ${ }^{[31,32]}$

\section{Pre-insertion counselling and ongoing support}

Adopt a 'LARC first' structured approach to contraceptive counsel-

ling. The content of contraceptive counselling heavily influences method selection, especially among younger women. ${ }^{[3-35]}$ While it is important to avoid coercion and ensure patient-centred, shared decision-making, we contend that it is time for a more directive approach, one in which women are explicitly informed that LARCs constitute first-line contraception. In this approach, counselling is standardised and methods are presented in order from most to least effective. ${ }^{[36]}$ Currently, it appears that during family planning counselling in SA, little attention is given to the relative effectiveness of different contraceptives, even though these can vary by as much as 100 -fold. ${ }^{[4,32]}$ Existing social media platforms, especially MomConnect and NurseConnect, have a key role to play in propagating messaging 
around 'LARCs first' and generating demand for these methods. Strategies targeting men are also required.

'Anticipatory guidance' before implant insertion can prepare women for sideeffects. ${ }^{[18]}$ The key topic to discuss before implant insertion is potential bleeding changes and the acceptability to the client within her sociocultural and relationship context. This is important, as changes in uterine bleeding patterns, while generally not harmful, are to be expected with implant use. Even though rates vary across studies, generally, of 100 women who use Implanon, $\sim 30$ will have no bleeding at all or no change to their normal bleeding patterns, 30 will have lighter, less frequent bleeding than usual, 15 - 20 will report prolonged, heavy nuisance bleeding, and 5 - 15 will experience intolerable bleeding resulting in implant removal (Fig. 2). ${ }^{[37-39]}$ Jadelle and a similar device, the Sino-implant, have fewer bleeding side-effects than Implanon. ${ }^{[13,37,40,41]}$ Continuation rates were also better with Jadelle than Implanon in several studies, ${ }^{[37,41]}$ but not in a multi-country

Women should be given written information, providing further explanation of changes in bleeding patterns that could be anticipated and the possibilities of treatment for these. ${ }^{[42]}$ While anticipatory guidance is likely to be useful, it is clearly difficult to fully prepare women for the reality of heavy or prolonged bleeding. Such bleeding patterns have substantial deleterious effects on a woman's comfort, on costs of sanitary protection and on sexual relations. In a study of SA women, considerably more married or cohabiting women removed the implant owing to bleeding side-effects than those who were single or in casual relationships, suggesting that implants may be especially suited to the latter groups. ${ }^{[32]}$ It is important, however, to consider the effects of the implant on overall sexual health, as randomised trial. ${ }^{[40]}$

most women do not experience increased bleeding and the certainty of highly effective contraception may, in fact, increase sexual pleasure. A study in the USA showed that $35 \%$ of implant users reported an improved sex life, $48 \%$ reported no change and $17 \%$ reported a worsened sex life. ${ }^{[4,3]}$

Actively follow-up implant users and strongly encourage them to return to the clinic for advice, reassurance, treatment of side-effects or implant removal, if desired. Women seldom return to the clinic to discuss problems encountered with the implant; instead, they rely on friends, the internet and social media to help them to decide whether to remove the implant. ${ }^{[44]}$ Social media contain many useful, accurate resources, presenting the implant from a patient's perspective, although admittedly alongside much misinformation. ${ }^{[45]}$ In a trial in India, actively following up implant users through phone calls or home visits was able to raise continuation rates. ${ }^{[46]}$ Calls, lasting 4 minutes on average, might be feasible in SA, given that women's contact details are routinely collected at each clinic visit, although these details are often incomplete and subject to frequent changes. ${ }^{[47]}$ Other studies examining active follow up had less promising findings, even though these were mostly in high-income countries and had weaker study designs. ${ }^{[48-50]}$

Intervene as soon as possible when bleeding is presented as a problem. Often, when women do return to the clinic for advice about side-effects, they are simply told to 'persevere' or 'wait and see'; ${ }^{[4,51]}$ yet, these encounters are critical, as they may be the final chance for supporting continuation of the method. The large majority of patients who present with problems subsequently remove the device. Supportive interventions at such visits appear to be especially effective at raising continuation among adolescents and young women. ${ }^{[52]}$ Health workers require a protocol for managing abnormal

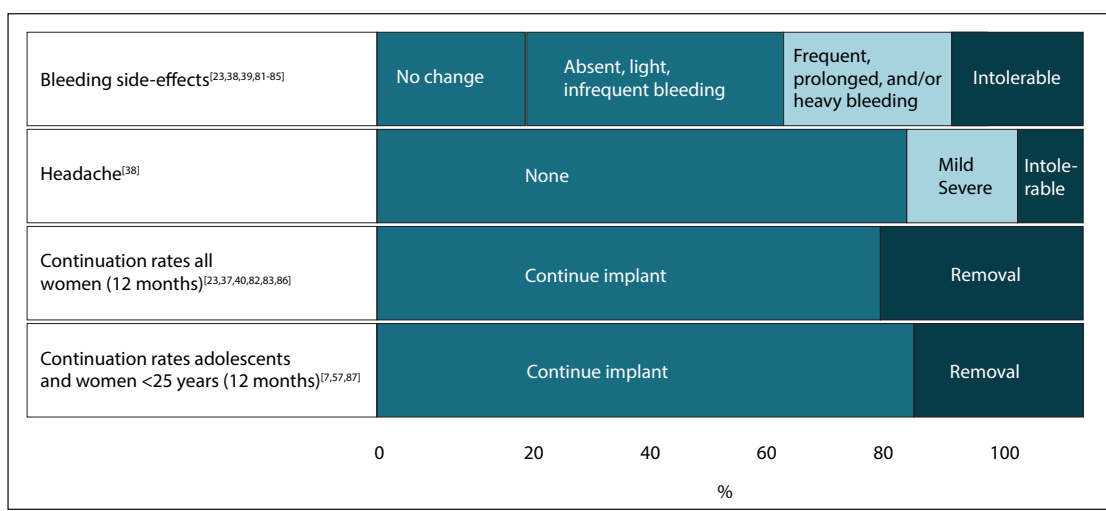

Fig. 2. Approximate continuation rates and likelihood of bleeding and headache side-effects. Rates of side-effects and of continuation vary between studies; the figures provided are indicative. bleeding, which encompasses the routine use of appropriate medications, including long-term therapies. Medications can include non-steroidal anti-inflammatory drugs, such as ibuprofen and mefenamic acid, and hormonal drugs, such as combined oral contraceptives or ethinyl oestradiol. ${ }^{[53]}$ Although health workers in SA commonly prescribe treatment for bleeding and headaches related to the implant, medication regimens vary considerably and a standardised approach is needed. ${ }^{[31,32]}$

Health workers' resistance to removals, or other failures in accessing removal services, will rapidly tarnish the implant's image and potentially undermine the entire family planning programme. Service delivery capacity for removals is a problem in many places $^{[54]}$ and women often resort to private sector providers. ${ }^{[32]}$ Opportunities for nurses to become skilled in implant removals were limited in the early years after implant introduction when demand for removals was low. In SA, this resulted in a number of botched removals or repeated unsuccessful attempts at removal, fuelling negative media and community coverage for the implant. ${ }^{[55]}$ Selected family planning nurses and doctors must be trained to perform removals and be counselled that they only encounter women with side-effects, which may give them a falsely negative impression of the method. The majority of women find the method highly satisfactory and therefore don't interface with the system until time of removal. In cases of difficult removals, either anticipated or after a single failed attempt at removal, nurses must immediately refer for expert support, rather than persisting in their efforts.

\section{Targeting of population groups}

Although suitable for 'any woman', the implant has been most successfully targeted at specific populations, most especially youth, first-time contraceptive users, and postpartum and post-abortion women. Making implants and other LARCS accessible for these groups must be considered a major priority for family planning in SA, signalling a step change for the national programme. Conducting a few rapid demonstration projects may provide the impetus needed for widespread implementation.

LARCs should be first-line contraceptive options for adolescents and young women. Counselling focused on the particular efficacy and benefits of LARCs is able to lower the rates of pregnancy and abortion in adolescents and young women. ${ }^{[56]}$ In one large study, two-thirds of youth were still using a LARC after 2 years, compared with 
only one-third of those who had selected a non-LARC method. In most studies, rates of implant continuation in young women were higher than in older women (Fig. 2)..$^{[7,57]}$

In Kenya, when implants were made available to young women seeking family planning, a quarter selected the method. ${ }^{[58]}$ In SA, such advances may be hampered by healthcare providers' opinions, which are often divergent from laws governing contraceptive access among adolescents. ${ }^{\left[{ }^{59]}\right.}$ Value judgements about sexual activity among youth may even lead to girls being denied contraceptives. The ongoing refusal to provide contraceptives in schools in the face of rising pregnancy rates among learners, can no longer be justified from a public health and gender equity perspective, and is at odds with World Health Organization guidance on safeguarding human rights in the provision of contraceptive services for young women. ${ }^{[60]}$ A national policy recommending LARCs as first-line contraception and in-school provision of these services, either through provision by visiting nurses or mobile clinics, would go a long way to overcoming these access barriers

Postpartum and post-abortion family planning services represent a critical pregnancy prevention tool that remains surprisingly under-utilised. Short inter-pregnancy intervals are associated with negative maternal and infant health outcomes, and an interval of at least 2 years between pregnancies is recommended ${ }^{[61]}$ More than 10 trials, including one in sub-Saharan Africa, ${ }^{[62]}$ have examined the safety, uptake and continuation rates of implant provision in the immediate postpartum period. ${ }^{[63]}$ Implants inserted within 48 hours postpartum appear not to affect lactation, growth, and neonatal and infant development. ${ }^{[64-66]}$ In a trial in the USA, ${ }^{[66]}$ as many as $90 \%$ of adolescents took up the offer of an implant after delivery, and uptake rates were also high in Uganda ${ }^{[62]}$ and Kenya. ${ }^{[67]}$

For postpartum LARC services to be successful, however, robust linkages are required between providers working in family planning, antenatal and labour wards. Counselling about postpartum LARC placement needs to begin during antenatal care. Attention is required to ensure that linkages between family planning providers and labour wards are robust enough to avoid undue delays in implant insertion, noting that many women are discharged within 24 hours of childbirth. If services are not streamlined, women may be instructed to return for implant insertion at their 6-week postpartum visit, which for many may mean that insertion will not occur. ${ }^{[63]}$

Most patients who have had an abortion wish to avoid a subsequent pregnancy and strongly desire a post-abortion contraceptive method. ${ }^{[68]}$ LARC use among these women appears more effective than short-acting contraception in reducing repeat pregnancies and abortions. ${ }^{[69,70]}$ In a multi-country trial, insertion of the implant immediately post abortion led to higher LARC use and reduced repeat pregnancies compared with insertion at a planned follow-up visit. ${ }^{[71]}$ Also, in a study in Ethiopia, implant insertion immediately post abortion resulted in $>80 \%$ of women leaving the facility with a contraceptive method compared with $58 \%$ before the services began. ${ }^{[72]}$ LARC use rose from $2 \%$ to $55 \%$.

Provision of the implant at HIV and tuberculosis clinics, including for women taking efavirenz, is a key priority. Current approaches to family planning service provision in HIV treatment programmes have had limited success in reducing unintended pregnancies among HIV-infected women. Women receiving antiretroviral treatment have frequent contact with health services, providing several opportunities for contraceptive provision. Reducing unintended pregnancies in these women would offer them considerable benefits, but also assist in reducing the number of HIV-infected children. In one study, however, in rural Mpumalanga, only a quarter of HIVinfected women had discussed family planning with their providers. ${ }^{[73]}$
There are substantial drug interactions between efavirenz and Implanon, considerably reducing drug levels of etonogestrel, the active drug in Implanon. ${ }^{[74-76]}$ Interactions between efavirenz and Jadelle appear even more pronounced than with Implanon. ${ }^{[77,78]}$ Women using an implant, who are also taking efavirenz, have higher pregnancy rates than those taking other antiretrovirals. The higher adherence to the implant, however, when compared with shortacting methods including injectable progestins, ${ }^{[79,80]}$ means that despite this drug interaction, the implant remains highly effective in these women - more so than short-acting alternatives. Available data therefore do not support limiting access to the implant in women taking efavirenz. ${ }^{[75]}$ Moreover, the use of efavirenz is likely to be phased out over time, alleviating many of these concerns.

\section{Conclusions}

The long-standing approach of prioritising contraceptive provision through family planning clinics may well account for the slow progress made in reducing unintended pregnancies in SA, including among adolescent girls. Making LARCs available in postpartum and postabortion wards, schools, and HIV and tuberculosis clinics, may help make considerable headway. At each contact with the health system, women of reproductive age should be asked about their fertility intentions and linked with LARC and other contraceptive services, as required. LARCs should be considered as first-line contraception for adolescents, young women and first-time contraceptive users; these groups should be actively targeted in schools and other services. The method may also be especially suitable for women in casual relationships or those who are single. Also, we recommend that demonstration projects be established, where nurses are recruited to work solely to provide LARCs and support implant provision more generally, especially in clinical outreach services. With additional training, existing lay healthcare workers could serve as advocates for LARCs and support their ongoing use once selected. Given the varying side-effects profile of implant devices, alternatives to Implanon might be considered, such as the Sino-implant.

The clinical management of implant users needs to be improved and women should be actively followed up and encouraged to return, should bleeding patterns or other side-effects become a problem. When a woman does seek advice, the opportunity must be capitalised upon to allow early medical management and/or implant removal, hence ensuring her ongoing confidence in services and in the use of the implant. Women who have difficulties accessing removal services or encounter health worker resistance to removal may understandably become resentful, stoking rumours and distrust in the method and in family planning services more generally. ${ }^{[54]}$ Responsive, quality removal services are required, performed by the appropriate level of health worker, with supportive expert referral when required. Even though the contraceptive efficacy of the implant is reduced in women taking efavirenz, the implant may still be more effective than alternative methods, and access to implants should not be restricted for women taking efavirenz, provided adequate counselling is offered. Together, the set of concerted actions outlined in this article could ensure that the implant fulfils its potential contribution to reducing unintended pregnancies in SA.

Acknowledgements. Candy Day, Health Systems Trust, for providing updated District Health Information System (DHIS) data.

Author contributions. HR and MFC wrote the initial draft. YP and SM provided critical inputs on subsequent iterations. All authors cleared the final article for submission. 
Funding. None.

Conflicts of interest. None.

1. National Department of Health. National Contraception and Fertility Planning Policy and Service Delivery Guidelines: A Companion to the National Contraception Clinical Guidelines. Pretoria: NDoH, 2012.

2. National Department of Health (NDoH), Statistics South Africa (Stats SA), South African Medical Research Council (SAMRC), and Inner City Fund (ICF). South Africa Demographic and Health Survey 2016: Key Indicators. 2017. http://www.statssa.gov.za/publications/Report\%2003-00-09/Report\%20032016: Key Indicators. 2017. http://www.sta
00-092016.pdf (accessed 3 September 2017).

3. Winner B, Peipert JF, Zhao Q, et al. Effectiveness of long-acting reversible contraception. N Engl J Med 2012;366(21):1998-2007. https://doi.org/10.1056/NEJMoa1110855

4. Trussell J. Contraceptive efficacy. In: Hatcher RATJ, Nelson AL, Cates W, Kowal D, Policar M, eds. Contraceptive Technology. 20th rev. ed. New York: Ardent Media, 2011.

5. Moodley J, Naidoo S, Wand H, Ramjee G. Contraception use and impact on pregnancy prevention in women participating in an HIV prevention trial in South Africa. J Fam Plann Reprod Health Care 2016;42(1):5-11. https://doi.org/10.1136/jprhc-2014-101100

6. Jacobstein R, Stanley H. Contraceptive implants: Providing better choice to meet growing family planning demand. Glob Health Sci Pract 2013;1(1):11-17. https://doi.org/10.9745/GHSPD-12-00003

7. Chiles DP, Roberts TA, Klein DA. Initiation and continuation of long-acting reversible contraception in the United States military healthcare system. Am J Obstet Gynecol 2016;215(3):e321-e329. https:// doi.org/10.1016/j.ajog.2016.03.027

8. Duvall S, Thurston S, Weinberger M, Nuccio O, Fuchs-Montgomery N. Scaling up delivery of contraceptive implants in sub-Saharan Africa: Operational experiences of Marie Stopes International. Glob Health Sci Pract 2014;2(1):72-92. https://doi.org/10.9745/GHSP-D-13-00116

9. O'Neil-Callahan M, Peipert JF, Zhao Q, Madden T, Secura G. Twenty-four-month continuation of reversible contraception. Obstet Gynecol 2013;122(5):1083-1091. https://doi.org/10.1097/AOG.0b013e3182a91f45

10. American College of Obstetricians and Gynecologists. ACOG Committee opinion no. 539. Adolescents and long-acting reversible contraception: Implants and intrauterine devices. 2012. www.acog.org/ Resources_And_Publications/Committee_Opinions/Committee_on_Adolescent_Health_Care/ Adolescents_and_Long-Acting_Reversible_Contraception (accessed 3 October 2017).

11. Committee on Adolescence. Contraception for adolescents. Pediatrics 2014;134(4):el244-e1256. https:// doi.org/10.1542/peds.2014-2299

12. McNicholas C, Maddipati R, Zhao Q, Swor E, Peipert JF. Use of the etonogestrel implant and levonorgestrel intrauterine device beyond the US Food and Drug Administration-approved duration. Obstet Gynecol 2015;125(3):599-604. https://doi.org/10.1097/aog.0000000000000690

13. Ali M, Akin A, Bahamondes L, et al. Extended use up to 5 years of the etonogestrel-releasing subdermal contraceptive implant: Comparison to levonorgestrel-releasing subdermal implant. Hum Reprod 2016;31(11):2491-2498. https://doi.org/10.1093/humrep/dew222

14. Massyn N, Peer N, Padarath A, Day C, eds. District Health Barometer 2016/17. Durban: Health Systems Trust, 2017.

15. Lince-Deroche N, Pleaner M, Morroni C, et al. Achieving universal access to sexual and reproductive health services: The potential and pitfalls for contraceptive services in South Africa. South African Health Review 2016;2016(1):95-108

16. ECHO Consortium. Evidence for Contraceptive Options and HIV Outcomes (ECHO) study. 2017. http://echo-consortium.com/ (accessed 4 September 2017).

17. Hathaway M, Torres L, Vollett-Krech J, Wohltjen H. Increasing LARC utilization: Any woman, any place, any time. Clin Obstet Gynecol 2014;57(4):718-730. https://doi.org/10.1097/grf.0000000000000071

18. Jacobstein R, Stanley H. Contraceptive implants: Providing better choice to meet growing family planning demand. Glob Health Sci Pract 2013;1(1):11-17. https://doi.org/10.9745/GHSP-D-12-00003

19. Neukom J, Chilambwe J, Mkandawire J, Mbewe RK, Hubacher D. Dedicated providers of long-acting reversible contraception: New approach in Zambia. Contraception 2011;83(5):447-452. https://doi. reversible contraception: New approach
org $/ 10.1016 /$.contraception.2010.08.021

20. Schaefer L. Task sharing implant insertion by community health workers: Not just can it work, but how Schaefer L. Task sharing implant insertion by community health workers: Not just can it work, but how
might it work practically and with impact in the real world. Glob Health Sci Pract 2015;3(3):327-329. might it work practically and with impact
https://doi.org/10.9745/ghsp-d-15-00230

21. Duvall S, Thurston S, Weinberger M, Nuccio O, Fuchs-Montgomery N. Scaling up delivery of contraceptive implants in sub-Saharan Africa: Operational experiences of Marie Stopes International. Glob Health Sci Pract 2014;2(1):72-92. https://doi.org/10.9745/GHSP-D-13-00116

22. Slabbert M, Venter F, Gay C, et al. Sexual and reproductive health outcomes among female sex workers in Johannesburg and Pretoria, South Africa: Recommendations for public health programmes. BMC Publ Health 2017;17(Suppl 3):442. https://doi.org/10.1186/s12889-017-4346-0

23. Gupta S, Mola G, Ramsay P, et al. Twelve month follow-up of a contraceptive implant outreach service in rural Papua New Guinea. Aust N Z J Obstet Gynaecol 2017;57(2):213-218. https://doi.org/10.1111/ ajo. 12596

24. Charyeva Z, Oguntunde O, Orobaton N, et al. Task shifting provision of contraceptive implants to community health extension workers: Results of operations research in Northern Nigeria. Glob Health Sci Pract 2015;3(3):382-394. https://doi.org/10.9745/ghsp-d-15-00129

25. Asnake M, Henry EG, Tilahun Y, Oliveras E. Addressing unmet need for long-acting family planning in Ethiopia: Uptake of single-rod progestogen contraceptive implants (Implanon) and characteristics of users. Int J Gynaecol Obstet 2013;123(Suppl 1):e29-e32. https://doi.org/10.1016/j.ijgo.2013.07.003

26. Weaver EH, Frankenberg E, Fried BJ, et al. Effect of village midwife program on contraceptive prevalence and method choice in Indonesia. Stud Fam Plann 2013;44(4):389-409. https://doi.org/10.1111/j.17284465.2013.00366.x

27. Austin-Evelyn K, Rabkin M, Macheka T, et al. Community health worker perspectives on a new primary health care initiative in the Eastern Cape of South Africa. PLoS ONE 2017;12(3):e0173863. https://doi org/10.1371/journal.pone.0173863

28. Harper CC, Rocca CH, Thompson KM, et al. Reductions in pregnancy rates in the USA with longacting reversible contraception: A cluster randomised trial. Lancet 2015;386(9993):562-568. https://doi. org/10.1016/s0140-6736(14)62460-0

29. Gibbs SE, Rocca CH, Bednarek P, et al. Long-acting reversible contraception counseling and use for older adolescents and nulliparous women. J Adolesc Health 2016;59(6):703-709. https://doi.org/10.1016/j. jadohealth.2016.07.018

30. Rahman M, Haider MM, Curtis SL, Lance PM. The Mayer Hashi large-scale program to increase use of long-acting reversible contraceptives and permanent methods in Bangladesh: Explaining the disappointing results. An outcome and process evaluation. Glob Health Sci Pract 2016:4(Suppl 2):S122-S139. https://doi. results. An outcome and process
org/10.9745/ghsp-d-15-00313

31. Adeagbo OA, Mullick S, Pillay D, et al. Uptake and early removals of Implanon NXT in South Africa: Perceptions and attitudes of healthcare workers. S Afr Med J 2017;107(10):822-826. https://doi.org/10.7196/ SAMJ.2017.v107i10.12821

32. Pillay D, Chersich MF, Morroni C, et al. User perspectives on Implanon NXT in South Africa: A survey of 12 public-sector facilities. S Afr Med J 2017;107(10):815-821. https://doi.org/10.7196/SAMJ.2017. v107i10.12833
33. Riney S, O'Shea B, Forde A. Etonogestrel implant as a contraceptive choice; patient acceptability and adverse effect profile in a general practice setting. Ir Med J 2009;102(1):24-25.

34. Whitaker AK, Quinn MT, Munroe E, et al. A motivational interviewing-based counseling intervention to increase postabortion uptake of contraception: A pilot randomized controlled trial. Patient Educ Coun 2016;99(10):1663-1669. https://doi.org/10.1016/j.pec.2016.05.011

35. Minnis AM, Mavedzenge SN, Luecke E, DehlendorfC. Provider counseling to young women seeking family planning services. Perspect Sex Reprod Health 2014;46(4):223-231. https://doi.org/10.1363/46e1414

36. Madden T, Mullersman JL, Omvig KJ, Secura GM, Peipert JF. Structured contraceptive counseling provide by the Contraceptive CHOICE Project. Contraception 2013;88(2):243-249. https://doi.org/10.1016/j. contraception.2012.07.015

37. Short M, Dallay D, Omokanye S, Stauch K, Inki P. Acceptability of long-acting, progestin-only contraception in Europe: A two-year prospective, non-interventional study. Eur J Contracept Reprod Health Care 2014;19(1):29-38. https://doi.org/10.3109/13625187.2013.862230

38. Blumenthal PD, Gemzell-Danielsson K, Marintcheva-Petrova M. Tolerability and clinical safety of Implanon: Eur I Contracept Reprod Health Care 2008:13(Suppl1):29-36. https/ldo. org/10.1080/13625180801960012

39. Darney P, Patel A, Rosen K, Shapiro LS, Kaunitz AM. Safety and efficacy of a single-rod etonogestre implant (Implanon): Results from 11 international clinical trials. Fertil Steril 2009;91(5):1646-1653. https://doi.org/10.1016/.jertnstert.2008.02.140

40. Bahamondes L, Brache V, Meirik O, et al. A 3-year multicentre randomized controlled trial of etonogestreland levonorgestrel-releasing contraceptive implants, with non-randomized matched copper-intrauterin device controls. Hum Reprod 2015;30(11):2527-2538. https://doi.org/10.1093/humrep/dev22

41. Berenson AB, Tan A, Hirth JM. Complications and continuation rates associated with 2 types of long-actin contraception. Am J Obstet Gynecol 2015;212(6):e761-e768. https://doi.org/10.1016/j.jajog.2014.12.028

42. Modesto W, Bahamondes MV, Bahamondes L. A randomized clinical trial of the effect of intensive versus non-intensive counselling on discontinuation rates due to bleeding disturbances of three long-acting reversible contraceptives. Hum Reprod 2014;29(7):1393-1399. https://doi.org/10.1093/humrep/deu089

43. Higgins JA, Sanders JN, Palta M, Turok DK. Women's sexual function, satisfaction, and perception after starting long-acting reversible contraceptives. Obstet Gynecol 2016;128(5):1143-1151. https://dol. org/10.1097/aog.0000000000001655

44. Lunde B, Littman L, Stimmel S, et al. 'Just wear dark underpants mainly': Learning from adolescents' and young adults' experiences with early discontinuation of the contraceptive implant. J Pediatr Adolesc Gynecol 2017;30(3):395-399. https://doi.org/10.1016/j.jpag.2016.12.006

45. Paul J, Boraas CM, Duvet M, Chang JC. YouTube and the single-rod contraceptive implant: A content analysis. J Fam Plann Reprod Health Care 2017;43(3):195-200. https://doi.org/10.1136 jfprhc-2016-101593

46. Hameed W, Azmat SK, Ali M, et al. Comparing effectiveness of active and passive client follow-up approaches in sustaining the continued use of long acting reversible contraceptives (LARC) in rural Punjab: A multicentre, non-inferiority trial. PLoS ONE 2016;11(9):e0160683. https://doi.org/10.1371/ journal.pone. 0160683

47. Pillay D, Morroni C, Pleaner M, et al. Gaps in monitoring systems for Implanon NXT services in South Africa: An assessment of 12 facilities in two districts. S Afr Med J 2017;107(10):827-831. https://doi. org/10.7196/SAMJ.2017.v107i10.12822

48. Steenland MW, Zapata LB, Brahmi D, Marchbanks PA, Curtis KM. The effect of follow-up visit or contacts after contraceptive initiation on method continuation and correct use. Contraception or contacts after contraceptive initiation on method continuation

49. Neuteboom K, de Kroon CD, Dersjant-Roorda M, Jansen FW. Follow-up visits after IUD-insertion: Sense or nonsense? A technology assessment study to analyze the effectiveness of follow-up visits after IUD insertion. Contraception 2003;68(2):101-104

50. Kirby D, Raine T, Thrush G, et al. Impact of an intervention to improve contraceptive use through followup phone calls to female adolescent clinic patients. Perspect Sex Reprod Health 2010;42(4):251-257 https://doi.org/10.1363/4225110

51. Dickson J, Hoggart L, Newton VL. Unanticipated bleeding with the etonogestrel implant: Advice an therapeutic interventions. J Fam Plann Reprod Health Care 2014;40(3):158-160. https://doi.org/10.1136/ jfprhc-2013-100817

52. Ravi A, Prine L, deFiebre G, Rubin SE. Beyond the surface: Care seeking among patients initiating contraceptive implant in an urban federally qualified health center network. J Prim Care Commun Health 2017;8(1):20-257. https://doi.org/10.1177/2150131916666011

53. World Health Organization. Selected Practice Recommendations for Contraceptive Use. 3rd ed. Geneva: WHO, 2016.

54. Kalmuss D, Davidson AR, Cushman LF, Heartwell S, Rulin M. Determinants of early implant discontinuation among low-income women. Fam Plann Perspect 1996;28(6):256-260. https://doi.org $10.2307 / 2136054$

55. Skosana I. Birth control implant needs a shot in the arm. Mail and Guardian, 29 May 2015.

56. Secura GM, Madden T, McNicholas C, et al. Provision of no-cost, long-acting contraception and teenage pregnancy. N Engl J Med 2014;371(14):1316-1323. https://doi.org/10.1056/NEJMoal400506

57. Diedrich JT, Klein DA, Peipert JF. Long-acting reversible contraception in adolescents: A systematic review and meta-analysis. Am J Obstet Gynecol 2017;216(4):e361-e364;e312. https://doi.org/10.1016/ ajog.2016.12.024

58. Hubacher D, Olawo A, Manduku C, Kiarie J. Factors associated with uptake of subdermal contraceptive implants in a young Kenyan population. Contraception 2011;84(4):413-417. https://doi.org/1016/. contraception.2011.02.007

59. Holt K, Lince N, Hargey A, et al. Assessment of service availability and health care workers' opinion about young women's sexual and reproductive health in Soweto, South Africa. Afr J Reprod Health 2012;16(2):283-293

60. Hoopes AJ, Chandra-Mouli V, Steyn P, Shilubane T, Pleaner M. An analysis of adolescent content in South Africa's contraception policy using a human rights framework. J Adolesc Health 2015:57(6):617623. https://doi.org/10.1016/j.jadohealth.2015.08.012

61. World Health Organization. Report of a WHO Technical Consultation on Birth Spacing. Geneva: WHO 2005

62. Averbach S, Kakaire O, Kayiga H, et al. Immediate versus delayed postpartum use of levonorgestrel contraceptive implants: A randomized controlled trial in Uganda. Am J Obstet Gynecol 2017 (in press). https://doi.org/10.1016/j.ajog.2017.06.005

63. Sothornwit J, Werawatakul Y, Kaewrudee S, Lumbiganon P, Laopaiboon M. Immediate versus delayed postpartum insertion of contraceptive implant for contraception. Cochrane Database Syst Rev 2017;(4):CD011913. https://doi.org/10.1002/14651858.CD011913.pub2

64. Braga GC, Ferriolli E, Quintana SM, et al. Immediate postpartum initiation of etonogestrel-releasing implant: A randomized controlled trial on breastfeeding impact. Contraception 2015.92(6):536-542 https://doi.org/10.1016/j.contraception.2015.07.009

65. Carmo L, Braga GC, Ferriani RA, Quintana SM, Vieira CS. Timing of etonogestrel-releasing implants and growth of breastfed infants: A randomized controlled trial. Obstet Gynecol 2017;130(1):100-107. https:// doi.org/10.1097/aog.0000000000002092

66. Bryant AG, Bauer AE, Stuart GS, et al. Etonogestrel-releasing contraceptive implant for postpartum adolescents: A randomized controlled trial. J Pediatr Adolesc Gynecol 2017;30(3):389-394. https://doi. org/10.1016/j.jpag.2016.08.003 
67. Shabiby MM, Karanja JG, Odawa F, et al. Factors influencing uptake of contraceptive implants in the immediate postpartum period among HIV infected and uninfected women at two Kenyan District immediate postpartum period among HIV infected and uninfected women at two
Hospitals. BMC Womens Health 2015;15:62. https:// $/$ oi.org/10.1186/s12905-015-0222-1

68. Kavanaugh ML, Carlin EE, Jones RK. Patients' attitudes and experiences related to receiving contraception during abortion care. Contraception 2011;84(6):585-593. https://doi.org/10.1016/j. contraception 2011.03.009

69. Cameron ST, Glasier A, Chen ZE, et al. Effect of contraception provided at termination of pregnancy and incidence of subsequent termination of pregnancy. Br J Obstet Gynaecol 2012;119(9):1074-1080. and incidence of subsequent termination of pregn

70. Hofmeyr GJ, Singata-Madliki M, Lawrie TA, Bergel E, Temmerman M. Effects of the copper intrauterine device versus injectable progestin contraception on pregnancy rates and method discontinuation device versus injectable progestin contraception on pregnancy rates and method discontinuation
among women attending termination of pregnancy services in South Africa: A pragmatic randomized among women attending termination of pregnancy services in South Africa: A pragmatic
controlled trial. Reprod Health 2016;13:42. https://doi.org/10.1186/s12978-016-0153-9

71. Hognert $\mathrm{H}$, Kopp Kallner $\mathrm{H}$, Cameron S, et al. Immediate versus delayed insertion of an etonogestrel releasing implant at medical abortion - a randomized controlled equivalence trial. Hum Reprod 2016;31(11):2484-2490. https://doi.org/10.1093/humrep/dew238

72. Samuel M, Fetters T, Desta D. Strengthening postabortion family planning services in Ethiopia: Expanding contraceptive choice and improving access to long-acting reversible contraception. Glo Health Sci Pract 2016;4(Suppl 2):S60-S72. https://doi.org/10.9745/ghsp-d-15-00301

73. Rodriguez VJ, Cook RR, Weiss SM, Peltzer K, Jones DL. Psychosocial correlates of patient-provider family planning discussions among HIV-infected pregnant women in South Africa. Open Access J Contracept 2017;8:25-33. https://doi.org/10.2147/oajc.s134124

74. Chappell CA, Lamorde M, Nakalema S, et al. Efavirenz decreases etonogestrel exposure: A pharmacokinetic evaluation of implantable contraception with antiretroviral therapy. AIDS 2017;31(14):1956-1972. https:// doi.org/10.1097/qad.000000000000159

75. Nanda K, Stuart GS, Robinson J, et al. Drug interactions between hormonal contraceptives and antiretrovirals. AIDS 2017;31(7):917-952. https://doi.org/10.1097/QAD.0000000000001392

76. Patel RC, Morroni C, Scarsi KK, et al. Concomitant contraceptive implant and efavirenz use in women living with HIV: Perspectives on current evidence and policy implications for family planning and HIV treatment guidelines. J Int AIDS Soc 2017;20(1):1-6. https://doi.org/10.7448/IAS.20.1.21396

77. Perry SH, Swamy P, Preidis GA, et al. Implementing the Jadelle implant for women living with HIV in a resource-limited setting: Concerns for drug interactions leading to unintended pregnancies. AIDS 2014;28(5):791-793. https://doi.org/10.1097/qad.0000000000000177
78. Scarsi KK, Darin KM, Nakalema S, et al. Unintended pregnancies observed with combined use of the levonorgestrel contraceptive implant and efavirenz-based antiretroviral therapy: A threeof the levonorgestrel contraceptive implant and efavirenz-based antiretroviral therapy: A three-
arm pharmacokinetic evaluation over 48 weeks. Clin Infect Dis 2016;62(6):675-682. https://doi. arm pharmacokinetic
org $/ 10.1093 /$ cid/civ1001

79. Pyra M, Heffron R, Mugo NR, et al. Effectiveness of hormonal contraception in HIV-infected women using antiretroviral therapy. AIDS 2015;29(17):2353-2359. https://doi.org/10.1097/QAD.0000000000000827

80. Patel RC, Onono M, Gandhi M, et al. Pregnancy rates in HIV-positive women using contraceptives and efavirenz-based or nevirapine-based antiretroviral therapy in Kenya: A retrospective cohort study. Lancet HIV 2015;2(11):e474-e482. https://doi.org/10.1016/S2352-3018(15)00184-8

81. Mansour D, Korver T, Marintcheva-Petrova M, Fraser IS. The effects of Implanon ${ }^{\star}$ on menstrual bleeding patterns. Eur J Contracept Reprod Health Care 2008;13(Suppl 1):13-28. https://doi. org/10.1080/13625180801959931

82. Ovre-Eide V, Skjeldestad FE. Use pattern for contraceptive implants in Norway. Acta Obstet Gynecol Scand 2016:95(11):1244-1250. https://doi.org/10.1111/aogs.13002

83. Roke C, Roberts $\mathrm{H}$, Whitehead A. New Zealand women's experience during their first year of Jadelle ${ }^{\circ}$ contraceptive implant. J Prim Health Care 2016;8(1):13-19. https://doi.org/10.1071/hc15040

84. Diedrich JT, Desai S, Zhao Q, et al. Association of short-term bleeding and cramping patterns with long-acting reversible contraceptive method satisfaction. Am J Obstet Gynecol 2015;212(1):e51-e58. https://doi.org/10.1016/..jajog.2014.07.025

85. Casey PM, Long ME, Marnach ML, Bury JE. Bleeding related to etonogestrel subdermal implant in a US population. Contraception 2011;83(5):426-430. https://doi.org/10.1016/j.contraception.2010.09.012 86. Peipert JF, Zhao Q, Allsworth JE, et al. Continuation and satisfaction of reversible contraception. Obstet Gynecol 2011;117(5):1105-1113. https://doi.org/10.1097/AOG.0b013e31821188ad

87. Abraham M, Zhao Q, Peipert JF. Young age, nulliparity, and continuation of long-acting reversible contraceptive methods. Obstet Gynecol 2015;126(4):823-829. https://doi.org/10.1097/ AOG.0000000000001036

Accepted 3 October 2017. 